\title{
PENGARUH BRAND IMAGE, TRUST, PERCEIVED PRICE DAN WWOM TERHADAP PURCHASE INTENTION SMARTPHONE DI JAKARTA
}

\author{
Deddy Saputra \\ Program Magister Manajemen Universitas Tarumanagara \\ deddy.117191027@stu.untar.ac.id
}

Masuk : 02-12-2020, revisi : 23-12-2020, diterima untuk diterbitkan : 23-12-2020

\begin{abstract}
The purpose of this research is to examine the influence of brand image, trust, perceived price and eWOM (electronic word of mouth) towards purchase intention smartphone on Jakarta. The populations are all smartphone user in Jakarta. The samples data number is collected from 220 respondents who lived in Jakarta, and aged between 21-30 years old who has chosen the smartphone.the data collection technique was carried out by distributing the questionnaires online using Google Form through social media (Whatsapp, Line, Instagram and Facebook). This research uses the non-probability sampling method with conveniece sampling technique. Multiple regression analysis is used to analyze research data by using SPSS Version 22 software. The result of this study has showed that brand image, trust, perceived price and eWOM have positive and significant effect on purchase intention smartphone in Jakarta.
\end{abstract}

Keywords: Brand Image, Trust, Perceived Price, eWOM, Purchase Intention

Abstrak: Tujuan dari penelitian ini adalah untuk menguji pengaruh brand image, trust, perceived price and eWOM (electronic word of mouth) terhadap purchase intention smartphone di Jakarta. Populasinya adalah seluruh pengguna smartphone di Jakarta. Jumlah sampel data dikumpulkan dari 220 responden yang berdomisili di Jakarta, berusia antara 2130 tahun yang telah memilih smartphone. Teknik pengumpulan data dilakukan dengan menyebarkan kuesioner secara online menggunakan Google Form melalui media sosial (Whatsapp, Line, Instagram dan Facebook). Penelitian ini menggunakan metode non probability sampling dengan teknik convenience sampling. Analisis regresi berganda digunakan untuk menganalisis data penelitian dengan menggunakan software SPSS versi 22. Hasil penelitian ini menunjukkan bahwa brand image, trust, perceived price dan eWOM berpengaruh positif dan signifikan terhadap purchase intentio smartphone di Jakarta.

Kata kunci: Brand Image, Trust, Perceived Price, eWOM, Purchase Intention

\section{PENDAHULUAN}

Perkembangan kemajuan teknologi informasi dan komunikasi dalam era digital ini sangat mempengaruhi kemampuan manusia dalam berkomunikasi yang didukung oleh kemampuan perangkat lunak dalam suatu sistem. Perangkat lunak yang digunakan untuk mendukung kemudahan ini tidak jarang dapat dijumpai dalam smartphone, baik dalam bentuk aplikasi browsing, chatting dan sebagainya. Pasar smartphone di Indonesia sekarang semakin kompetitif. Gagasan ini didukung oleh informasi yang tercantum dalam laporan terbaru, yang menunjukkan perbandingan market share antara brand yang teratas sangat tipis, hanya 1 poin. Dari lembaga riset pasar yang mengeluarkan hasil laporan riset mereka terkait market smartphone Indonesia selama Q3-2019 adalah dari Counterpoint. Yang menariknya, hasil riset tersebut menampilkan daftar TOP 5 berbeda dari Q3-2018 sebelumnya. Dari sumber resmi Counterpoint, bisa diketahui bahwa penguasa market smartphone Indonesia selama di Q3-2019 adalah Samsung (22\%) menduduki posisi pertama, menyusul Xiaomi (20\%) menduduki posisi kedua, disusul lagi sama OPPO (19\%) menduduki posisi ketiga, posisi keempat adalah VIVO (13\%), dan posisi terbawah adalah Realme (11\%). Purchase intention muncul ketika seseorang 
telah mendapatkan informasi yang cukup mengenai produk yang diinginkan. Purchase intention adalah perilaku yang muncul sebagai respon terhadap objek, atau juga pembelian ulang Henry Assael (1998). Menurut Schiffman dan Kanuk (2007) menyebutkan adanya pengaruh eksternal, munculnya kebutuhan akan suatu produk, pengenalan produk dan evaluasi informasi merupakan hal yang dapat menimbulkan suatu minat beli konsumen. Pentingnya bagi perusahaan untuk membuat rencana strategi pemasaran yang efektif guna meningkatkan purchase intention smartphone. Setiap pengguna memiliki tujuan penggunaan atau fitur dari suatu smartphone untuk keperluannya sehari-hari, contohnya smartphone digunakan sebagai alat gaming, alat komunikasi, sebagai alat yang dipergunakan untuk kerja atau berbisnis secara mobile. Jadi industri gadget atau pasar smartphone terus berkembang pesat dan penting untuk memahami faktor yang mempengaruhi purchase intention pada pengguna smartphone. Terdapat beberapa variabel yang dapat mempengaruhi purchase intention. Berdasarkan penelitian yang dilakukan oleh Ping (2017) variabel brand image, perceived price, perceived quality, perceived value memiliki pengaruh terhadap purchase intention. Dalam penelitian Che et al. (2015) variabel brand image, perceived price, trust, dan value memiliki pengaruh terhadap purchase intention. Lebih lanjut, menurut Jalilvand dan Samiei (2012) menyebutkan variabel eWOM dan brand image mempunyai pengaruh terhadap purchase intention. Sementara penelitian menurut Thurau et al. (2004) menjelaskan variabel eWOM (electronic word of mouth) juga memiliki pengaruh yang signifikan terhadap purchase intention.

\section{TINJAUAN PUSTAKA}

\section{Brand Image}

Menurut Kotler dan Keller (2016:330), Brand Image didefinisikan sebagai "the extrinsic properties of the product or service, including the ways in which the brand attempts to meet customer's psychological or social needs", atau sifat ekstrinsik suatu produk atau layanan, termasuk cara-cara merek berusaha memenuhi kebutuhan psikologis atau sosial pelanggan.

Trust

Menurut Chinomona (2016:127) "trust can be defined as extent to which a consumer believes that a certain brand, he or she has confidence in satisfies his or her desire." Trust merupakan sejauh mana konsumen percaya bahwa merek tertentu yang dia percayai dapat memuaskan keinginannya

\section{Perceived Price}

Menurut Kim et al. (2012:243) "Perceived price is considered to be the perceived level monetary price for one vendor in comparison with prices of other vendor." Perceived price dianggap sebagai tingkat moneter yang dipersepsikan untuk satu vendor dibandingkan dengan harga dari vendor lainnya.

$\boldsymbol{e W O M}$

Menurut Hennig-Thurau, et al. (2004:39) eWOM didefinisikan sebagai "any positive or negative statement made by potential, actual, or former customers about a product or company, which is made available to a multitude of people and institutions via the Internet." eWOM didefinisikan sebagai pernyataan positif atau negatif apapun yang dibuat oleh calon pelanggan, pelanggan aktual, atau mantan pelanggan tentang suatu produk atau perusahaan, yang tersedia untuk banyak orang dan lembaga melalui internet.

\section{Kaitan Antara Variabel}

\section{Kaitan antara Brand Image dan Purchase Intention}

Penelitian yang dilakukan Che et al. (2015) dan didukung oleh Luki dan Keni (2020) menyatakan bahwa brand image sangat mempengaruhi purchase intention secara positif. Mereka mengemukakan bahwa perusahaan harus mencurahkan upaya untuk mempertahankan dan meningkatkan brand image, dengan asosiasi merek yang dikelola dengan baik termasuk peningkatan manfaat fungsional, simbolik, dan pengalaman, yang akan menghasilkan brand 
image yang disukai. Hasil penelitian tersebut juga didukung oleh penelitian dari yang menyatakan bahwa brand image adalah yang paling berpengaruh terhadap purchase intention. $\mathrm{H}_{1}$ : Brand image memiliki pengaruh positif terhadap purcahse intention smartphone di Jakarta Kaitan antara Trust dan Purchase Intention

Menurut penelitian yang dilakukan Keni et al. (2020), dan dukungan Irda dan Isnalita (2018) ditemukan bahwa trust memiliki pengaruh positif dan signifikan terhadap purchase intention. Seseorang mempunyai trust yang tinggi terhadap suatu produk bisa membuat merek untuk tumbuh lebih kuat, karena trust mempunyai peran penting dalam menentukan keberhasilan suatu produk di pasar.

$\mathrm{H}_{2}$ : Trust memiliki pengaruh positif terhadap purchase intention smartphone di Jakarta.

\section{Kaitan antara Perceived Price dan Purchase Intention}

Penelitian yang dilakukan oleh Wang dan Chen (2016) menjelaskan bahwa perceived price mempunyai efek langsung dan positif terhadap purchase intention. Konsumen menganggap harga sebagai sinyal kualitas ekstrinsik utama ketika pengetahuan produk mereka terbatas. Oleh karena itu, komsumen akan melihat produk dengan harga yang lebih tinggi sebagai produk yang lebih berkualitas. Selain itu penelitian ini didukung oleh Ping (2017) yang menyatakan bahwa perceived price mempengaruhi purchase intention secara positif dan signifikan. Persepsi masyarakat terhadap harga berbeda karena berbagai pengaruh dari berbagai faktor.

$\mathrm{H}_{3}$ : Perceived price memiliki pengaruh positif terhadap purchase intention smartphone di Jakarta.

\section{Kaitan antara $e$ WOM dan Purchase Intention}

Menurut Jalilvand dan Samiei (2012) dan Wenny dan Keni (2018), eWOM juga mempunyai pengaruh yang positif dan signifikan terhadap purchase intention. eWOM memainkan peran penting yang dapat menciptakan citra sebuah merek perusahaan sehingga memiliki efek langsung yang kuat pada purchase intention. Konsumen dapat membaca rekomendasi online untuk suatu produk yang secara langsung mungkin memiliki efek yang kuat pada keputusan pembelian mereka.

$\mathrm{H}_{4}$ : eWOM memiliki pengaruh positif terhadap purchase intention smartphone di Jakarta. penelitian:

Berdasarkan uraian pengertian dan kaitan antar variabel, maka berikut adalah model

\section{Gambar 1 \\ Model Penelitian}

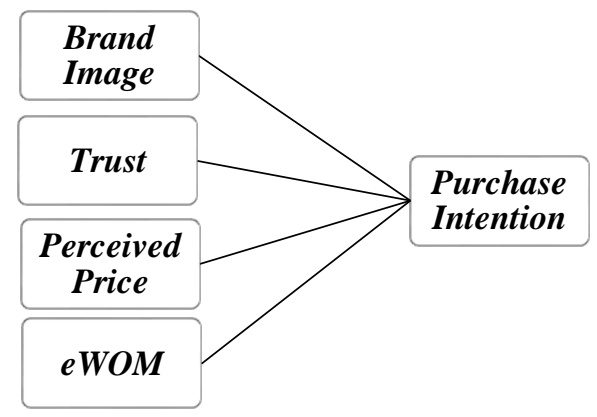

\section{METODOLOGI PENELITIAN}

Dalam penelitian ini, jenis metode penelitian yang digunakan adalah penelitian deskriptif dengan kategori pengumpulan data berupa cross sectional. Sampel yang ditargetkan adalah seluruh pengguna smartphone dan bertempat tinggal di Jakarta. Metode pengambilan sampel menggunakan metode non-probability sampling dengan teknik convenience sampling. Penyebaran data menggunakan kuesioner melalui media online Google Form. Sampel yang digunakan dalam penelitian ini adalah sebanyak 220 responden, mayoritas responden berjenis kelamin Wanita (50.9\%), berusia 21-30 tahun (74,5\%), Pendidikan terakhir SMK/SMA, 
Pekerjaannya pegawai swasta/negeri (54,5\%), Pengeluaran kisaran $<$ Rp.4.500.000, bertempat tinggal di Jakarta Barat (42,7\%). Indikator penelitian yang digunakan dalam penelitian ini dapat dilihat pada tabel berikut ini.

\section{Tabel 1}

Indikator Pengukuran Variabel

\begin{tabular}{|c|c|c|}
\hline Variabel & Item & Sumber \\
\hline Brand Image & 4 item & Che et al. (2016) \\
\hline Trust & 4 item & Che et al. (2016) \\
\hline Perceived Price & 4 item & Che et al. (2016) \\
\hline eWOM & 6 item & Jalilvand dan Samiei (2012) \\
\hline Purchase Intention & 3 item & Erkan dan Evans (2016) \\
\hline
\end{tabular}

Dalam penelitian ini, teknik analisa data yang digunakan dalam menganalisis penelitian adalah dengan bantuan software SPSS 22, meliputi beberapa analisa tambahan dengan uji validitas dan reliabilitas, uji normalitas, uji multikolinearitas, uji heteroskedastisitas, analisis regresi ganda, uji-t, uji-F, dan uji $R$-Square.

\section{HASIL DAN PEMBAHASAN}

Hasil analisis reliabilitas dan validitas dapat menunjukkan bahwa variabel (brand image, trust, perceived price, eWOM dan purchase intention) adalah valid dan realiabel. Dinyatakan valid karena nilai corrected item-total correlation untuk semua butir pernyataan pada setiap atribut sudah lebih besar dari 0,2 dan dapat dikatakan reliabel karena nilai Cronbach Alpha lebih besar dari 0,70. Hal ini menyatakan bahwa kuesioner sebagai alat ukur data responden yang layak untuk di lanjutkan ke analisis selanjutnya.

Selanjutnya pada hasil analisis data bagian pengujian asumsi klasik yang dilakukan, pertama adalah uji normalitas, melalui normal probability plot (p-p plot), dapat diketahui bahwa residual data menyebar disekitar garis diagonal dan mengikuti arah garis diagonal, maka model regresi tersebut masih memenuhi asumsi normal.

Kedua adalah uji multikoliniearitas, bahwa nilai VIF dari sejumlah variabel brand image, trust, perceived price, dan $e W O M$ lebih kecil dari 10, maka dapat disimpulkan bahwa tidak terdapat gejala multikolinearitas dari model regresi tersebut.

Ketiga adalah uji heteroskedastisitas, hasil penelitian menunjukkan grafik scatterplots bahwa titik-titik menyebar diatas dan di bawah angka nol dari sumbu Y, maka model 1 memiliki kesamaan variansi atau tidak terjadi heteroskedastisitas. Dengan demikian data hasil kuesioner lulus dari pengujian asumsi klasik.

Selanjutnya, analisis regresi ganda bahwa trust mempunyai pengaruh positif yang paling besar diantara variabel yang lain yaitu nilai koefisien regresi $(\beta)=0,332$, sedangkan brand image memiliki pengaruh nilai koefisien regresi $(\beta)=0,307$, kemudian perceived price memiliki pengaruh nilai koefisien regresi $(\beta)=0,195$ dan terakhir $e W O M$ memiliki pengaruh nilai koefisien regresi $(\beta)=0,145$ dan signifikan terhadap variabel purchase intention.

Berdasarkan hasil pengujian hipotesis (uji-F) adalah dimana semua variabel yang diuji telah menunjukkan angka signifikasi lebih kecil dari 0,05 . Hal ini menyatakan bahwa $\mathrm{H}_{0}$ ditolak, sehingga dapat disimpulkan bahwa variabel brand image $\left(\mathrm{H}_{1}\right)$, trust $\left(\mathrm{H}_{2}\right)$, perceived price $\left(\mathrm{H}_{3}\right)$ dan eWOM $\left(\mathrm{H}_{4}\right)$ diterima secara bersama-sama dan memiliki pengaruh terhadap purchase intention pada smartphone di Jakarta.

Setelah itu adalah hasil pengujian (uji-t) menjelaskan bahwa semua variabel yang diteliti berpengaruh positif dan signifikan terhadap purchase intention karena angka signifikansi lebih kecil dari $\alpha=0,05$. Jadi dapat disimpulkan $\mathrm{H}_{\mathrm{o}}$ ditolak. Artinya menyatakan bahwa untuk variabel brand image $\left(\mathrm{H}_{1}\right)$, trust $\left(\mathrm{H}_{2}\right)$, perceived price $\left(\mathrm{H}_{3}\right)$ dan eWOM $\left(\mathrm{H}_{4}\right)$ diterima dan memiliki pengaruh positif dan signifikan terhadap purchase intention pada smartphone di Jakarta.

Berdasarkan hasil pengujian nilai R-Square $\left(\mathrm{R}^{2}\right)$ adalah sebesar 0,681 yang berarti $68,1 \%$ (nilainya yang besar karena mendekati angka satu). Jadi bisa dinyatakan bahwa variabel brand 
image, trust, perceived price, dan eWOM dapat memberikan informasi yang dibutuhkan untuk memprediksikan variabel purchase intention, sedangkan sisanya $(100 \%-68,1 \%)=31,9 \%$ akan dijelaskan oleh variabel-variabel lain yang tidak termasuk dalam penelitian.

Selanjutnya hasil penelitian menunjukkan bahwa variabel brand image $\left(\mathrm{H}_{1}\right)$, trust $\left(\mathrm{H}_{2}\right)$, perceived price $\left(\mathrm{H}_{3}\right)$ dan $e W O M\left(\mathrm{H}_{4}\right)$ tidak ditolak karena memiliki pengaruh positif terhadap purchase intention pada smartphone di Jakarta. Hasil penelitian ini didukung oleh Che et al. (2015) dan Luki dan Keni (2020), menyatakan bahwa brand image mempengaruhi purchase intention secara positif. Jadi brand smartphone selalu memahami apa kemauan dan keinginan dari konsumen adalah salah satu faktor penting dalam menentukan image dari sebuah brand untuk memiliki dampak yang baik pada brand image dalam menambahkan nilai tambah suatu produk terhadap purchase intention. Lebih lanjut, hasil penelitian ini didukung oleh Keni et al. (2020) dan Irda dan Isnalita (2018), ditemukan bahwa trust memiliki pengaruh positif terhadap purchase intention. Dengan selalu memberikan espektasi dan hasil yang memuaskan sehingga membuat brand untuk tetap bertumbuh lebih kuat dan mempunyai peran penting dalam menentukan keberhasilan produk dipasar, dengan hasil tersebut bisa memperdalam hubungan trust konsumen kepada brand dalam meningkatkan purchase intention. Kemudian, hasil penelitian ini dilakukan oleh Wang dan Chen (2016) dan Ping (2017), menjelaskan bahwa perceived price mempunyai efek langsung dan positif terhadap purchase intention. Dengan demikian brand mendapatkan respon yang positif dari masyarakat akan ketertarikannya menggunakan produk dari brand smartphone ini, sehingga tetap mempertahankan harga penawaran yang bervariasi dari segmen menengah ke bawah hingga menengah keatas dan kualitas produk yang kompetitif dibandingkan dengan yang lain, maka dengan penawaran harga yang baik dan terjangkau bisa meningkatkan purchase intention. Setelah ini, hasil penelitian ini dilakukan oleh Jalilvand dan Samiei (2012) dan Wenny dan Keni (2018), eWOM juga mempunyai pengaruh yang positif dan signifikan terhadap purchase intention. Jadi review online ini menjadi salah satu faktor pertimbangan yang penting bagi konsumen yang memiliki niat untuk membeli smartphone. sebagai satu brand pada industri smartphone dapat membuat kegiatan event bersama-sama mengulas dan testimoni produk smartphone langsung dengan selebgram, dan review dari youtuber tentang gadget di lokasi seperti mall, modern store dan sebagainya secara tidak langsung bisa meningkatkan purchase intention.

\section{KESIMPULAN DAN SARAN}

Dari hasil penelitian dan pengolahan data yang sudah dilakukan dapat disimpulkan bahwa brand image, trust, perceived price, dan eWOM memiliki pengaruh positif terhadap purchase intention smartphone di Jakarta.

Penelitian ini dilakukan dengan harapan dapat memberikan kontribusi literatur yang baik terhadap karya tulis maupun ilmiah baik secara akademis ataupun secara praktis. Pertama, berdasarkan hasil yang telah didapatkan bahwa mayoritas responden dalam penelitian ini beranggapan bahwa brand image pada brand smartphone sudah mempunyai image dengan reputasi yang baik dan positif dikalangan responden, sehingga membuat responden tetap selalu mengingat brand smartphone. Saran dari peneliti kepada adalah untuk tetap mempertahankan mutu dan kualitas produk brand dan guna meningkatkan brand imagenya agar selalu bisa meningkatkan image yang kuat untuk dikemudian hari agar membuat konsumen tetap mengingat pada brand smartphone sehingga secara tidak langsung meningkatkan purchase intention. Kedua, hasil dari penelitian ini menunjukkan bahwa mayoritas responden beranggapan bahwa trust terhadap brand smartphone sudah baik sehingga responden menunjukkan niat yang positif dan kuat terhadap brand. Hal ini dapat memberikan saran kepada brand untuk selalu mempertahankan hubungan dekat antara brand dengan responden serta meningkatkan rasa trust konsumen yang cukup baik pada saat ini. Ketiga, hasil dari penelitian ini menunjukkan mayoritas responden menilai bahwa perceived price terhadap brand smartphone memiliki harga produk yang cukup murah dan terjangkau sesuai dengan 
kualitas yang didapatkan, jadi dapat membuat konsumen mempunyai keinginan untuk membeli. Masukan dari peneliti kepada brand smartphone adalah untuk selalu berusaha melindungi harga dalam batas wajar dan kualitas produk yang ditawarkan kepada konsumen dikemudian hari. Terakhir, hasil penelitian memperlihatkan bahwa mayoritas responden menunjukkan bahwa eWOM kepada brand smartphone bisa berupa informasi ulasan produk dari konsumen langsung yang pernah membeli dan menggunakan produk tersebut. Informasi yang didapatkan bisa berupa pengetahuan produk, bagaimana meyakinkan untuk membeli, serta informasi seputar produk brand smartphone. Saran dari peneliti kepada brand smartphone adalah untuk mempertahankan dan selalu menjalin komunikasi yang baik kepada konsumen agar bisa semakin banyak orang yang mendapatkan ulasan informasi dari konsumen lainnya melalui media sosial dan internet (Youtube, Facebook, dan Instagram).

\section{DAFTAR PUSTAKA}

Assael, H. (1998). Consumer Behavior and Marketing Action, 6th Edition. New York University.

Chinomona, R. (2016). Brand communication, brand image and brand trust as antecedents of brand loyalty in Gauteng Province of South Africa. African Journal of Economic and Management Studies, 7(1).

Cheng-Ping, L. (2017). Effects of brand image, perceived price, perceived quality, and perceived value on the purchase intention towards sports and tourism products of the 2016 Taichung international travel fair, The Journal of International Management Studies, 12(2).

Hennig-Thurau, T., et. al. (2004). Electronic word-of-mouth via consumer-opinion platforms: what motivates consumers to articulate themselves on the internet? Journal of interactive marketing, 18(1), 38-52.

Jalilvand, M. R. \& Samiei, N. (2012). The effect of electronic word of mouth on brand image and purchase intention. Marketing Intelligence \& Planning, 30, 460-476.

Keni, K., Lerbin, R., A., R., Ary, S., P., (2020). The Impact of Trust, satisfaction, and people's pride on purchasing intention in the Indonesia batik sector. The Future Opportunities and Challenges of Business in Digital Era 4.0 - Bangsawan et al. (eds) 2020 Taylor \& Francis Group, London. (ICEBE).

Kim, H. W., Xu, Y., \& Gupta, S. (2012). Which is more important in internet shopping, perceived price or trust? Electronic Commerces, 11, 241-252

Kustiwi, I. \& Isnalita. (2018). Trust and Purchasing Intention in E-Commerce: Lazada Indonesia. 10.2991/iccsr-18.2018.7.

Kotler, P., \& Keller, K. L. (2016). Marketing Management, 15th Edition. Pearson Education, Inc

Lien, Che. H., et. al. (2015). Online hotel booking: The effects of brand image, price, trust and value on purchase intentions. Asia Pacific Management Review xx, 1-9.

Luki, L. H., \& Keni (2020) Pengaruh brand awareness, brand image dan customer perceived value terhadap purchase intention. Jurnal Manajemen Bisnis dan Kewirausahaan, 4(3), 81-86.

Schiffman, L. G., \& Kanuk, L. L. (2007). Consumer Behaviour. New Jersey: Pearson Prentice Hall.

Wenny, K. S., \& Keni (2018). Pengaruh social network marketing (SNM) dan electronic word of mouth (EWOM) terhadap minat beli pelanggan. Jurnal Manajemen Bisnis dan Kewirausahaan, 2(6), 68-73. 